\title{
Association of Psychological Capital and Job Adaptability in the Nurses of Kashan University of Medical Sciences Hospital, Iran
}

\author{
Hamid Rahimi ${ }^{1}$, Fatemeh Baghsheykhi ${ }^{2}$, Esmaeil Azizi ${ }^{3}$, Somayeh Haji Jafari ${ }^{4}$
}

\begin{abstract}
Background \& Aims: Job adaptability in nurses is a combination of psychological and non-psychological factors, which are of particular importance for the continuation of their successful employment. Nonpsychological factors include all the tools and equipment that an employed individuals uses to perform the tasks in a job. Psychological or internal factors encompass the feelings or attitudes of individuals toward their job and determine their relationship with their job. On the other hand, stress and the subsequent incompatibility and low job satisfaction among nurses could threaten their physical and mental health and quality of life, acting as a barrier to achieving their individual and social development goals. The main assumption in the theory of job adaptability is that the individual intends to achieve and maintain a positive relationship with the work environment. Individuals put their needs into their work environment, and the work environment also imposes demands on the individuals. Job adaptability is optimal when the individual and environment have aligned working needs with their professional skills. Job adaptability is influenced by positive organizational behavior and positive psychological personality traits, which highlight the concept of psychological capital. Psychological capital is a phenomenon that has recently been expressed in the field of organization and management, showing a high potential for the improvement of the health and performance of various individuals employed in diverse work environments. This concept is measurable and effective in development and management to improve performance in modern work environments. Job adaptability plays a key role in continuing the successful employment of nurses, which could be affected by psychological capital. Various factors are involved in psychological capital, including the individual's belief in their ability to succeed, perseverance in pursuing goals, positive relationship, and enduring defined problems with characteristics (e.g., self-confidence and striving to succeed in challenging tasks [self-efficacy], optimism, hope, and resilience). Psychological capital is a positive aspect of human life and is defined by the personal understanding of individuals, having goals to achieve success, and perseverance in the face of adversity. In the present study, selfefficacy, optimism, hope, and resilience were considered as the main components of psychological capital. Job adaptability is essential to the successful employment of nurses, which could be largely influenced by psychological capital. The present study aimed to investigate the association between psychological capital and job adaptability in the nurses employed at the hospitals affiliated to Kashan University of Medical Sciences, Iran.

Materials \& Methods: This descriptive-correlational study was conducted on 542 nurses employed at the hospitals affiliated to Kashan University of Medical Sciences in 2018. In total, 190 nurses were selected via stratified random sampling. Out of 440 female nurses, 154 cases, and out of 102 male nurses, 46 cases were selected as the sample size. The estimated sample size was 190, while 178 questionnaires were returned with the rate of 0.93 . Correspondingly, statistical analysis was performed on 178 participants, with the test power and significance level calculated to be 0.93 after the preliminary analysis and adequacy based on the test power. Data were collected using the standard psychological capital questionnaire (Luthans et al., 2007) with 23 items

\footnotetext{
1. Associate Professor, Department of Education, Faculty of Humanities, University of Kashan, Kashan, Iran (Corresponding author) Tel: $09133064430 \quad$ Email: dr.hamid.rahimi@ kashanu.ac.ir

2. MA, Department of Education, Faculty of Humanities, University of Kashan, Kashan, Iran

3. Assistant Professor, Department of Nursing, School of Nursing and Midwifery, Kashan University of Medical Sciences, Kashan, Iran

4. MA Student in Nursing, School of Nursing and Midwifery, Kashan University of Medical Sciences, Kashan, Iran
} 
and job adaptability questionnaire (Dawis and Lofquist, 1984) with 35 items, which were scored based on a five-point Likert scale. The content validity of the tools was examined by 10 professors and specialists, and the construct validity was confirmed via confirmatory factor analysis. In terms of psychological capital, the component of hope (0.88), and in terms of job adaptability, the component of comfort value $(0.65)$ had the highest weight and factor load. The reliability of the questionnaires was estimated at 0.85 for psychological capital and 0.83 for job adaptability using the Cronbach's alpha coefficient. Data analysis was performed in SPSS version 16 using descriptive statistics (frequency, percentage, mean, and standard deviation) and inferential statistics (Pearson's correlation-coefficient, one-sample t-test, and regression analysis) at the significance level of $\mathrm{P}<0.05$. In addition, t-test was applied for the comparison of the mean psychological capital with the hypothesized mean of four and job adaptability with the hypothesized mean of three. Pearson's correlation-coefficient was used to determine the correlation between psychological capital and job adaptability, and the regression analysis was employed to predict job adaptability based on psychological capital.

Results: Among all the nurses in the sample group, the majority were female and had a bachelor's of science degree, work experience of 1-10 years, and formal employment status, and were married or married with one child or no children. The mean psychological capital $(5.41 \pm 0.77)$ was above the average of four, and the mean job adaptability $(3.23 \pm 0.43)$ was above the average of three. Pearson's correlation-coefficient indicated a positive, significant correlation between the psychological capital and job adaptability of the nurses $(r=0.43)$. In addition, the most significant association was observed between psychological capital and value orientation $(\mathrm{r}=0.43)$, while the least significant correlation was denoted between psychological capital and autonomy $(\mathrm{r}=0.15)$. In other words, the higher psychological capital status of the nurses resulted in the higher job adaptability.

Conclusion: According to the results, the implementation of programs for the improvement of the psychological capital of the nursing community could promote the job adaptability of nurses. Furthermore, a supportive view within hospitals toward nurses and the subsequent perception of being supported on behalf of nurses could effectively enhance their job adaptability. Since the status of psychological capital and job compatibility among the nurses was relatively favorable and the fact that psychological capital could be learned and developed, to achieve a more favorable and standardized situation in this regard, it is recommended that hospital officials invite experienced psychologists and professors in this field to consider regular training courses for nurses. In the process of the selection and recruitment of nurses, proper tests should also be used to measure their psychological capital level to employ supervisors with higher psychological capital.

Keywords: Psychological Capital, Job Adaptability, Nurse

\section{Conflict of Interest: No}

How to Cite: Rahimi H, Baghsheykhi F, Azizi E, Haji Jafari S. Association of Psychological Capital and Job Adaptability in the Nurses of Kashan University of Medical Sciences Hospital, Iran. Iran Journal of Nursing. 2019; 32(118):31-42.

Received: 6 March 2019

Accepted: 10 Jun 2019 


\title{
رابطه سر مايه روانشناختى با سازتارى شغلى بر ستار ان بيمار ستان دانشكاه علوم بزشكى كاشان
}

\author{
حميد رحيمى'، فاطمه باغ شيخى '، اسماعيل عزيزى'، سميه حاجى جعفرى
}

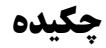

زمينه و هدف: ساز كارى شغلى براى ادامه اشتغال موفقيت آميز برستار ان عامل مهمى به شمار مىرود كه مىتواند تحت تاثير سرمايه روانشناختى قرار

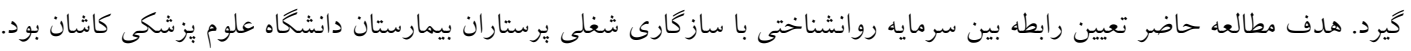

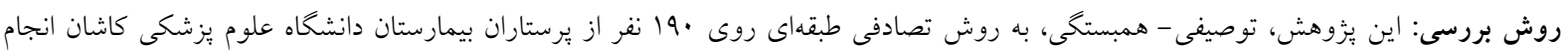

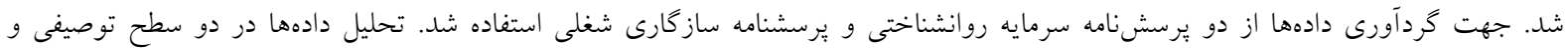

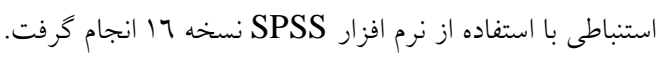

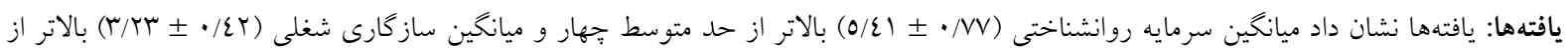
حد متوسط سه است. ضريب همبستخى بيرسون نشان داد بين سرمايه روانشناختى و سازگارى شغلى (r=/2r) رابطه مستقيم و معنى دار وجود دارد.

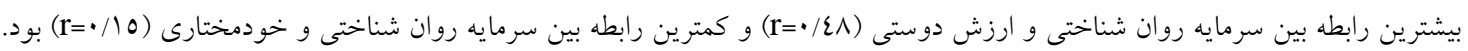

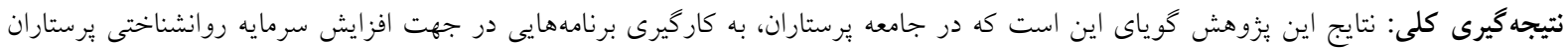

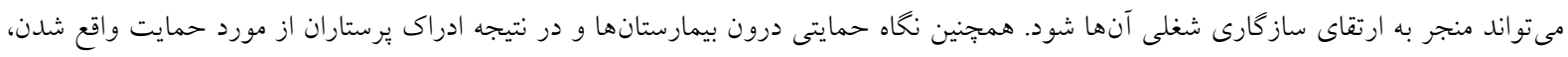

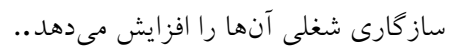

كليد وازهها: سرمايه روانشناختى، ساز گارى شغلى، يرستار

تعارض منافع: ندارد

تاريخ دريافت:

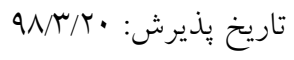

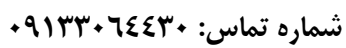

'. دانشيار، كروه علوم تربيتى، دانشكده علوم انسانى، دانشكاه كاشان، كاشان، ايران (نويسنده مسئول) Email: dr.hamid.rahimi@ kashanu.ac.ir

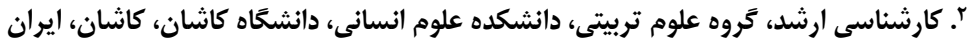

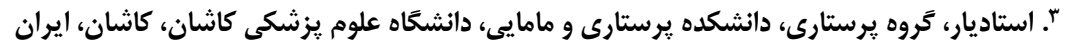

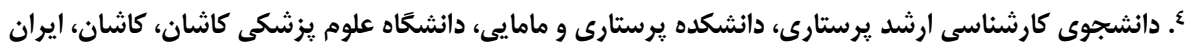


است. افراد، نيازهاىشان را وارد محيط كارى مى كنند و محيط كار نيز از فرد مطالباتى دارد و سازكارى كارى وارى داريط زمانى در بهترين حالت است كه فرد و محيط، نيازهاى داى دارد

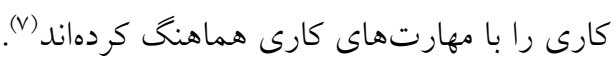

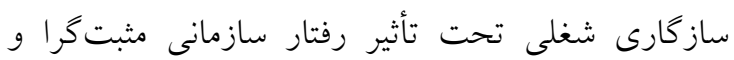
ويزگىهاى فردى مثبت روانشناختى است كه مفهوم سرمايه روانشناختى را به ذهن متبادر مىسازد. سرمايه

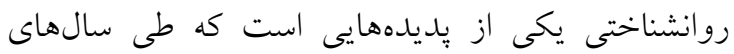
اخير به حوزة سازمان و مديريت وارد شده است و ظرفيت بالقوه بالايى را براى ارتقاء سلامتى و عملكرد

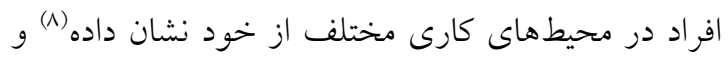
قابل اندازهيرى، توسعه و مديريت اثربخش براى بهبود

عملكرد در محيطهاى كارى امروزى است (9). سرمايه روانشناختى، باور فرد به توانيىهايش براى

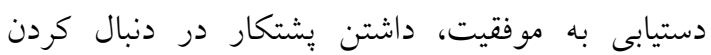

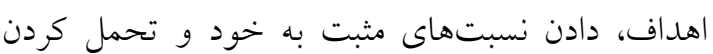
مشكلات تعريف شده(·) و با ويزگى هايى مانند داشتن اعتماد به نفس لازم و تلاش براى موفقيت در كارهاى نعرئ

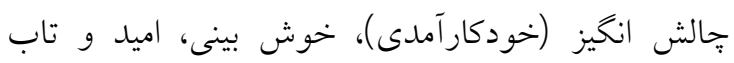
آورى (11) برجسته مىشود. سرمايه روان شناختى جنبه

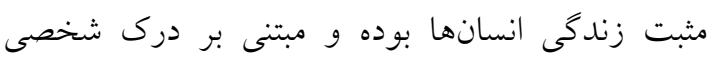
خود، داشتن هدف براى رسيدن به موفقيت و بايدارى در

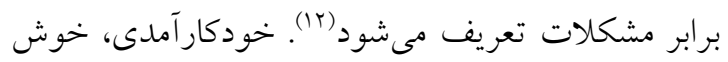
بينى، اميد و تاب آورى، جهار مؤلفه اصلى سرمايه

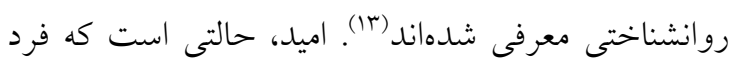
را قادر مىسازد تا اهداف و انتظارات واقع بينانه اما جالشى را تعيين كند و از طريق خودرهبرى، نيروى اراده، انرزى و حس كنترل درونى به آن اهداف دست يابد (ع). خوشبينى و بدبينى نيز به ترتيب به عنوان انتظار نتايج

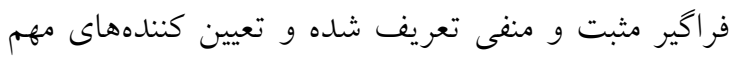

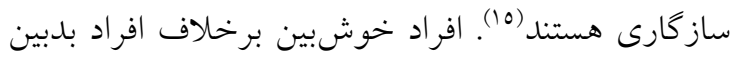

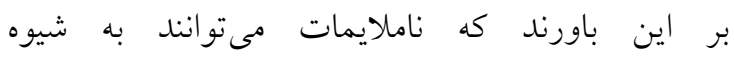

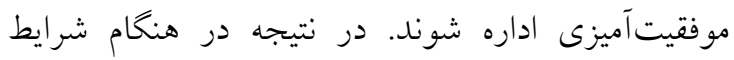
استرسآور نيز احساس كتترل خود را از دست نمىدهند

\section{مقدمه}

سازمان جهانى بهداشت، يرستاران را ستون فقرات سيستم

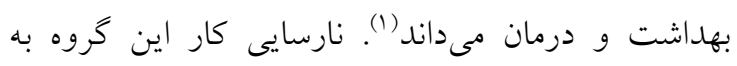
علت نقش مهم آنها در بهبود بيامدهاى بيماران، نتايج

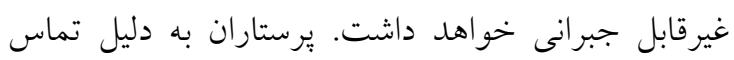
با بيماران و فشاركارى بالا، بيوسته با مشكلات كارى و و ودئه

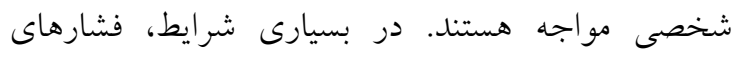

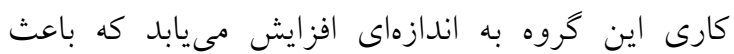

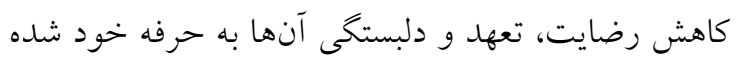

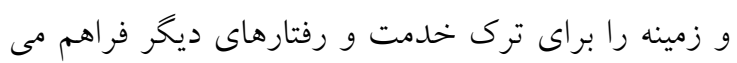

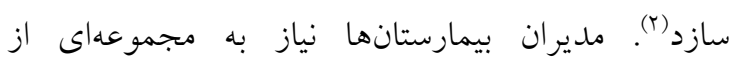

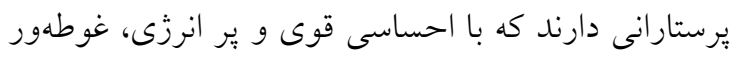
در كار باشند و با شغل و محيط كارى شان ساز كارى بيدا كرده باشند. به نظر مىرسد وجود يُرستاران ساز كار با كار

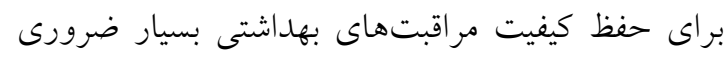

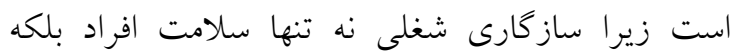

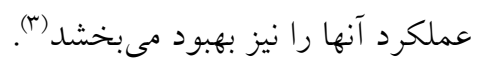

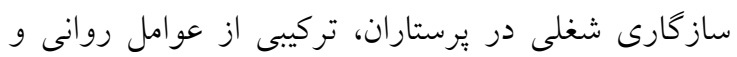

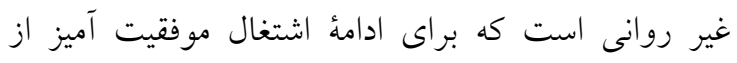
اهميت ويزهاى برخوردار است. عوامل غير روانى شامل رله

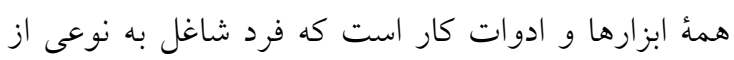

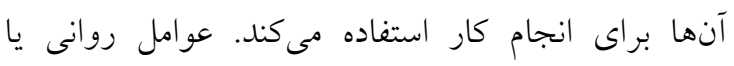

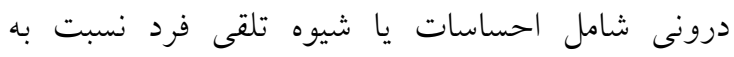

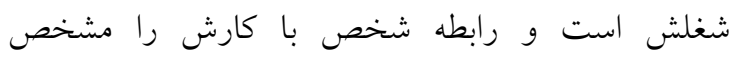

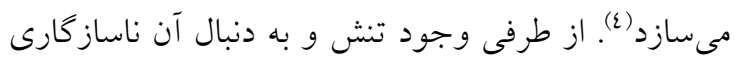

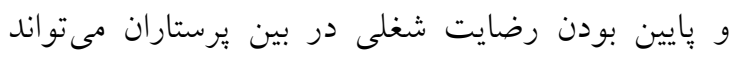

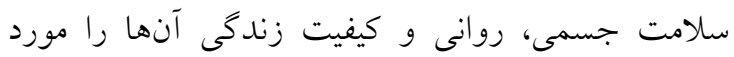

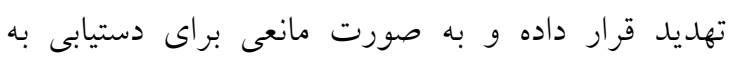

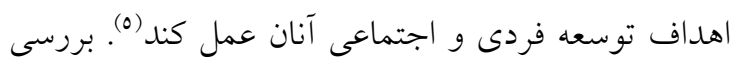
ها نشان مىدهد كه به درصد يرستاران مرتباً تحت تأثير عوامل استرس زاى محيط كار قرار مى گيرند كه مىتواند

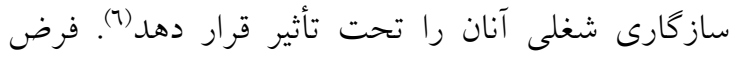
اصلى در نظريه سازكارى شغلى اين است كه فرد، خواهان دستيبى و حفظ ارتباط مثبت با محيط كارى 
تعويق انداختن وظايف(TV) و بهبود نخرش كاركنان، تغيير

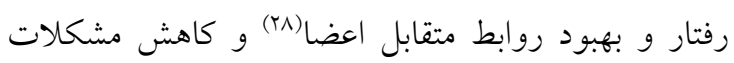

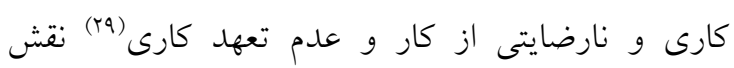

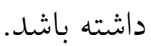

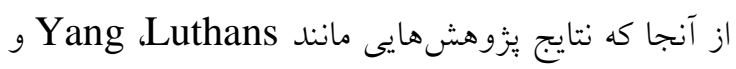

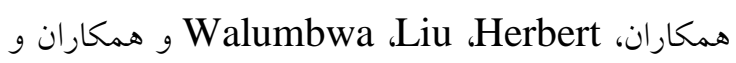
هilva كاهش هر كدام از مشكلات كارى بوده است؛ ممكن

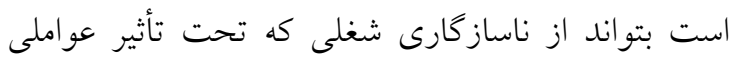
مانند فشارهاى محيط كار، احساس درماندكى، بدبينى،

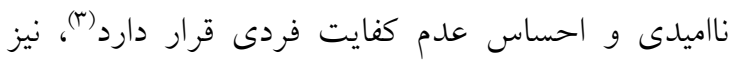

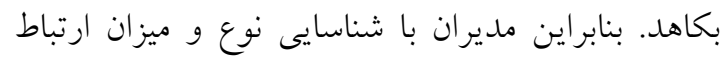

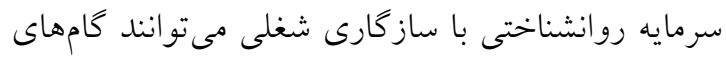

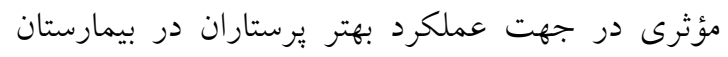
بردارند.

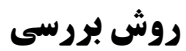

يزوهش حاضر يك مطالعه توصيفى همبستكى بود. جامعه

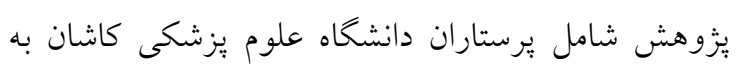

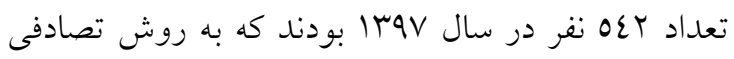
طبقهاى تعداد ،19 نفر به عنوان نمونه انتخاب كرديد.

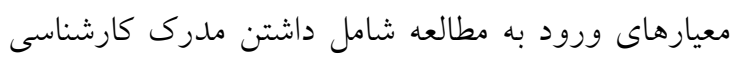
يرستارى و حداقل يك سال سابقه كار در بيمارستان بود.

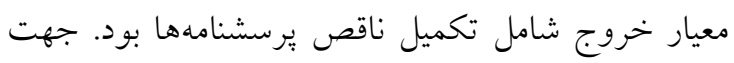

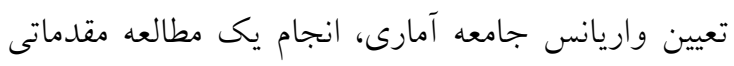
روى تعدادى از يرستاران ضرورت داشت. بنابراين تعداد

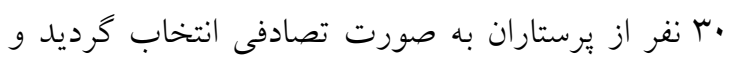

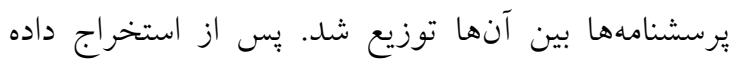

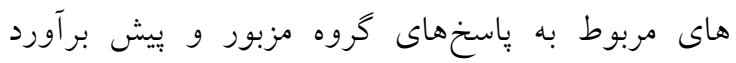

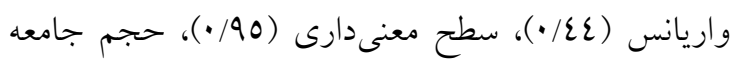

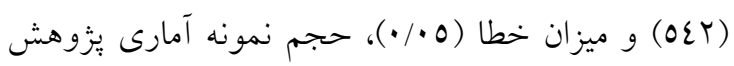

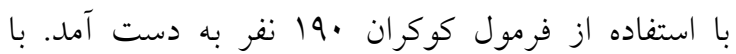

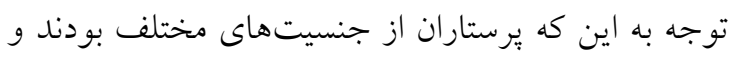

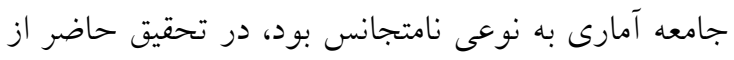

و با تلاش و وييخيرى به تغييرات مثبت و سازنده دست

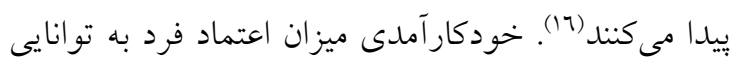

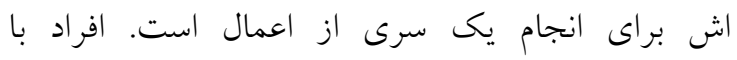

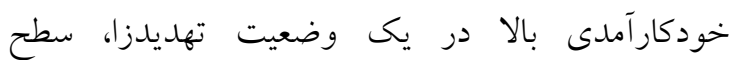

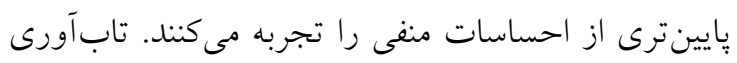

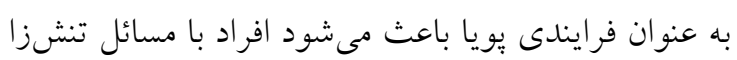

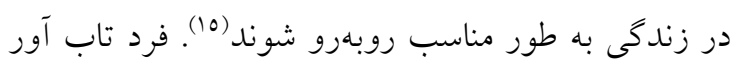

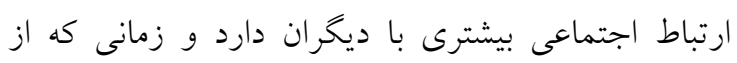

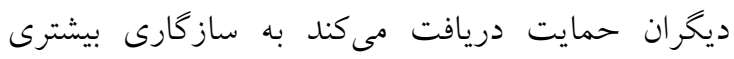
دست مى ديابد (IV). بنابراين به نظر مىرسد وجود سرمايه روان شناختى بالا

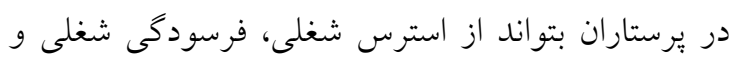
ساير علائم منفى بكاهد و باعث سازگًارى شغلى بيشتر

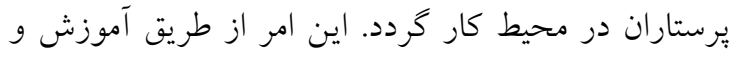
ارتقاى سرمايه روانشناختى در يرستاران امكان يذّير است. در سالهاى اخير يُزوهشهاى فراوانى در رابطه سرمايه

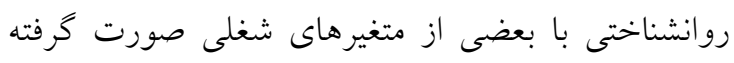

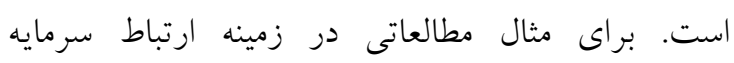

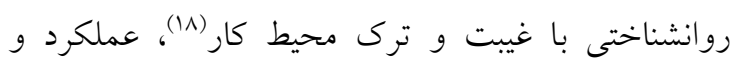

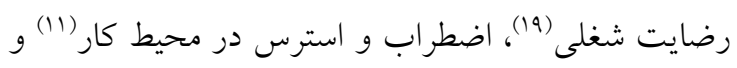

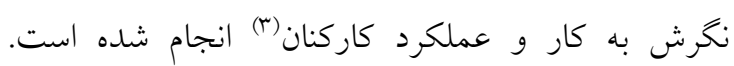

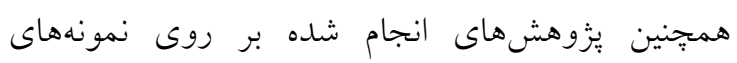

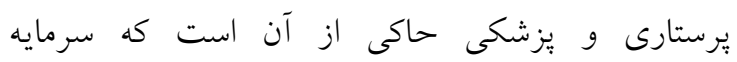

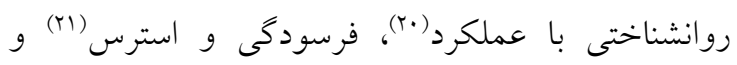

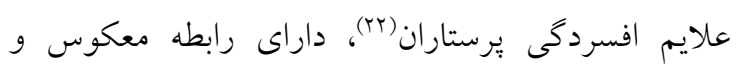

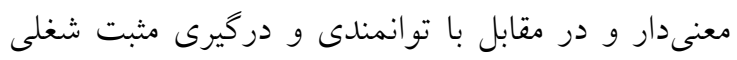

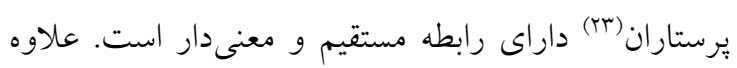
بر آن تحقيقات نشان مىدهند كه سرمايه روانشناختى

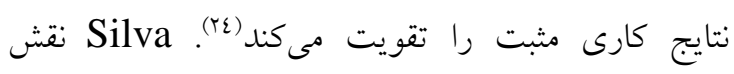

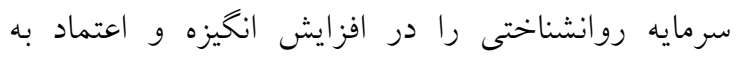
نفس Hodges نقش سرمايه روانشناختى در كاهش وانش احساس عدم كفايت شغلى و افزايش سطح عملكرد

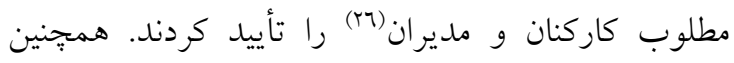
سرمايه روانشناختى مىتواند در كاهش تعلل كارى و به مرديه 
سئوال)، ارزش نوع دوستى (ينج سئوال)، ايمنى (شش

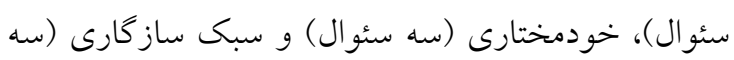

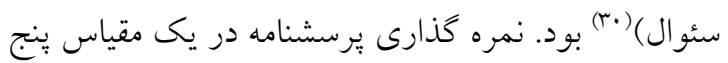

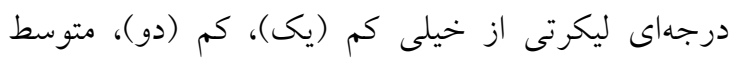

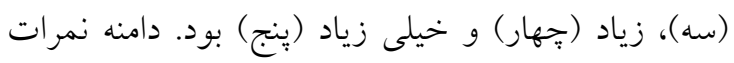

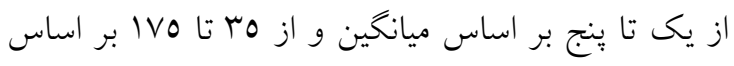

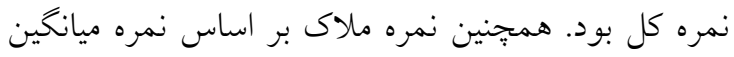

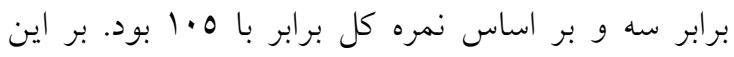

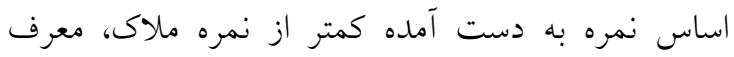
وضعيت نامطلوب فرد و نمره به دست آمده بيشتر از نمره ملاك، معرف وضعيت مطلوب فرد در متغير ساز گارى شغلى بود.

روايى ابزارها به صورت محتوايى توسط •ا نفر از اساتيد و متخصصان و به صورت روايى سازه از طريق تحليل عاملى تأييدى مورد بررسى قرار كرفت. از طريق تحليل

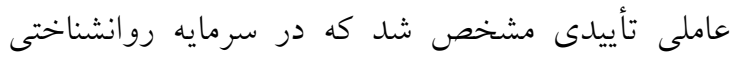

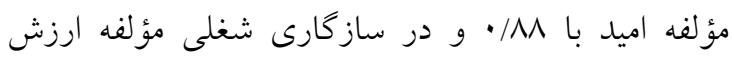
راحتى با 70/• داراى بيشترين وزن و بار عاملى بودند.

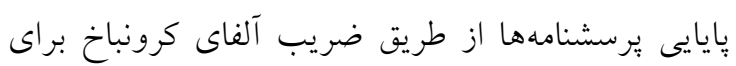

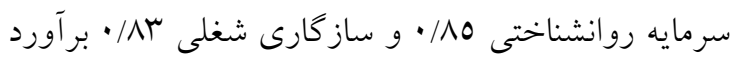

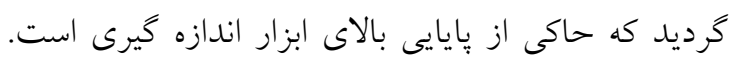

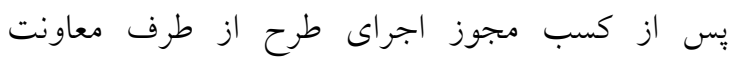
يُزوهشى دانشخاه علوم يزشكى كاشان (با كد اخلاق IR.KAUMS.NUHEPM.REC.1397.059 تاريخ (1) (1) از تمامى شركت كنندكان، رضايت نامه شركت در مطالعه كرفته شد و به ايشان اطمينان داده شد كه يرسشنامها بدون نام خواهند بود، نتايج محرمانه

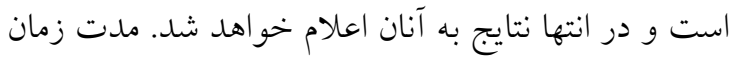
مناسبى براى ير كردن يُرسشنامه طرح در نظر كرفته شد.

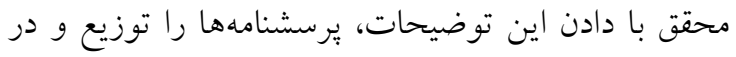
مدت سه هفته، تكميل و جمع آورى نمود. تحليل دادها بها در دو سطح توصيفى (فراوانى، درصد، ميانخين و انحراف

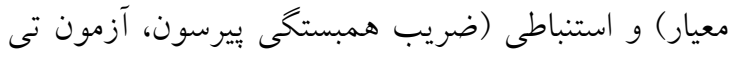

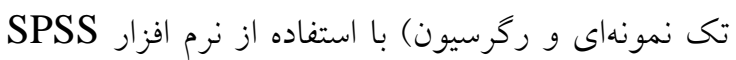

روش نمونه كيرى طبقهاى متناسب با حجم استفاده شد. بر

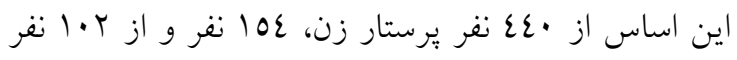

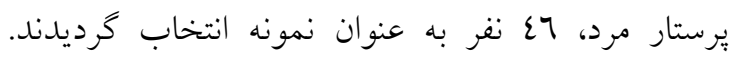

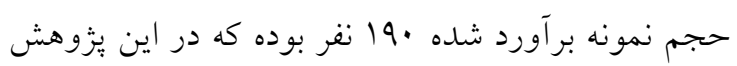

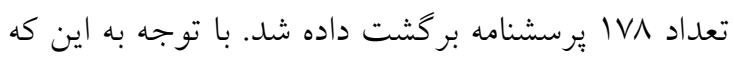

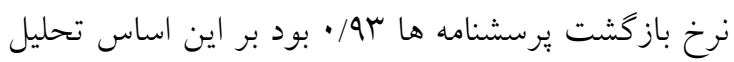

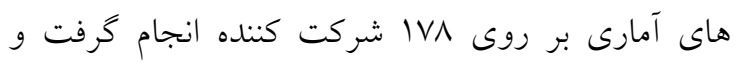

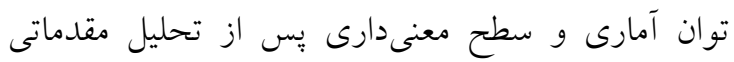

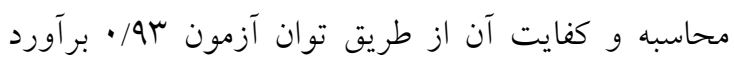
كرديد. ابزار مورد استفاده در اين يزّوهش، در قالب سه آنه

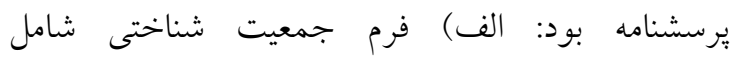

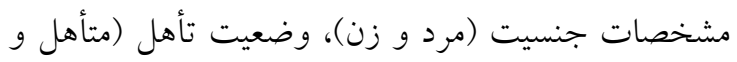

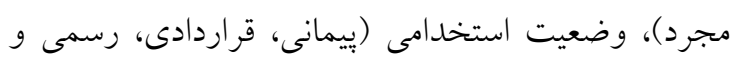

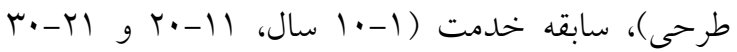
سال)، مدرى تحصيلى (كارشناسى و كارشناسى ارشد و

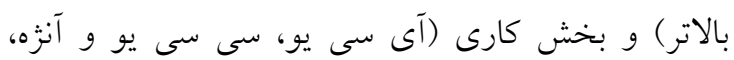

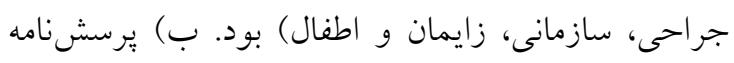

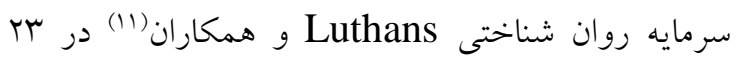
كويه در جهار مؤلفه اميد (شش سئوال)، تاب آورى (ينج

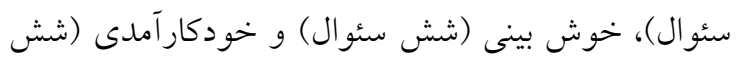

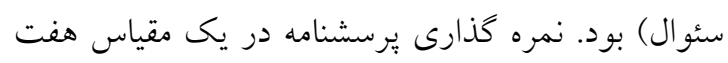

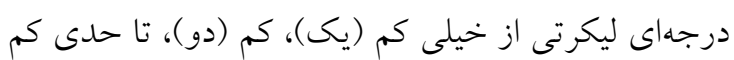

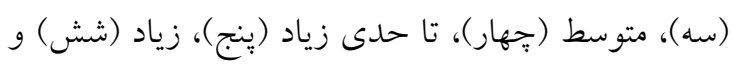

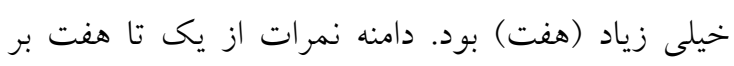

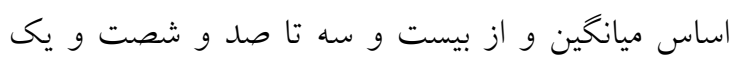
بر اساس نمره كل بود. همجنين نمره ملاك بر اساس نمره

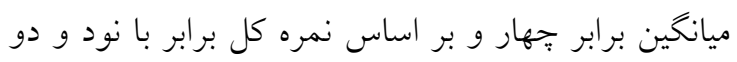

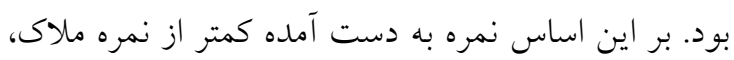
معرف وضعيت نامطلوب فرد و نمره به دست آمده بيشتر از نمره ملاك، معرف وضعيت مطلوب فرد در متغير سرمايه روانشناختى بود.

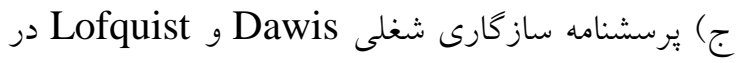
قالب Or كويه بر اساس هفت مؤلفه ارزش بيشرفت (سه

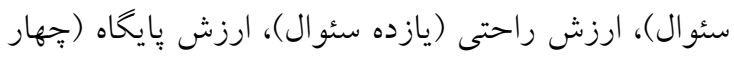


نسخه 17 انجام كرفت. سطح معنى دارى در آزمونها طبق جدول شماره ا، از مجموع يرستاران گروه نمونه، P P > در نظر کرفته شد. از آزمون تى تكى نمونهاى اكثر پيرستاران زن، داراى مدرى كارشناسى با سابقه جهت مقايسه ميانخين سرمايه روانشناختى با ميانكين خدمت ا تا • ا سال، وضعيت استخدامى رسمى، از نظر فرضى جهار و سازگارى شغلى با ميانكين فرضى سه، از وضعيت تأهل، متأهل و داراى يك فرزند يا بدون فرزند ضريب همبستخى بيرسون جهت تعيين رابطه بين سرمايه بودند. روان شناختى و سازگارى شغلى و از رگرسيون خطى براى بيش بينى سازكارى شغلى از روى سرمايه روانشناختى استفاده گرديل.

\begin{tabular}{|c|c|c|c|}
\hline \multicolumn{4}{|c|}{ جدول شماره (: مشخصات فردى تروه نمونه } \\
\hline درصد & فراوانى & سطوح & متغير \\
\hline r. & m & 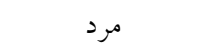 & جنسيت \\
\hline$\wedge \cdot$ & IEY & زن ان & \\
\hline $9 \cdot$ & 17. & كارشناسى & مدرى تحصيلى \\
\hline $1 \cdot$ & 11 & ارشد و بالاتر & \\
\hline$r$ & rv & بيمانى & \\
\hline 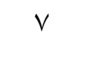 & ir & قراردادى & وضعيت استخدامى \\
\hline 07 & 99 & رسمى & \\
\hline IV & $r \cdot$ & طرحى & \\
\hline ro & 乏o & مجرد & وضعيت تأهل \\
\hline vo & 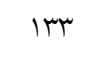 & متأهل & \\
\hline 9 & 17 & آى سى يو & \\
\hline$r \varepsilon$ & 71 & سى سى يو و آنثه & \\
\hline 17 & r^ & جراحى & بخش كارى \\
\hline $1 \cdot$ & 11 & سازمانى & \\
\hline m & 00 & زايمان و اطفال & \\
\hline$r \cdot$ & or & يك فرزند & \\
\hline rı & 0. & دو فرزند & ت ت تعداد فرزندان \\
\hline$r$ & 0 & سه فرزند و بيشتر & \\
\hline$\varepsilon$. & vi & بدون فرزند & \\
\hline 70 & 117 & 1-1·1 سال & \\
\hline MT & or & $r \cdot-11$ & سابقه خدمت \\
\hline$r$ & 0 & $r \cdot-r l$ & \\
\hline
\end{tabular}

بالاتر از حد متوسط سه است. آزمون تى نشان داد با توجه به سطح معنى دارى، ميانخين سرمايه روان شناختى و سازگارى شغلى برستاران در سطح خطاى 0 • • معنى دار است و فرض ادعاى يزوهشخر تأييد مىشود.
تحليل جدول شماره r نشان داد ميانخين سرمايه روان شناختى (OVV) • (O//) و همه ابعاد آن بالاتر از حد

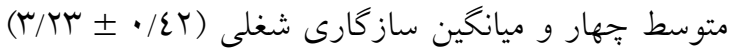
و همه ابعاد آن به جز خودمختارى و سبك ساز گارى 
جدول شماره ז: آزمون t تكى نمونهاي جهت مقايسه ميانكَين سرمايه روان شناختى و ساز كارى شغلى

\begin{tabular}{|c|c|c|c|c|c|c|}
\hline $\mathbf{p}$ & درجه آزادى & $\mathbf{t}$ & ميانخين جامعه & ميانخين و انحر اف استاندارد & تعداد & متغير \\
\hline$\cdot / \cdots 1$ & IVV & $r 7 / V$ & $\varepsilon$ & $0 / 79 \pm \cdot / \Lambda \varepsilon$ & IVA & خود كارآمدى \\
\hline 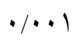 & IVV & $\mathrm{IV} / \mathrm{VV}$ & $\varepsilon$ & $0 / r า \pm 1 / \cdot r$ & IVA & اميد \\
\hline$\cdot \cdots 1$ & IVV & $19 / 0 \mathrm{~V}$ & $\varepsilon$ & $0 / T V \pm \cdot / \Lambda T$ & IVA & تاب آورى \\
\hline$\cdot 1 \cdot \cdot 1$ & IVV & $1 / / 11$ & $\varepsilon$ & $0 /$ TO $\pm \cdot / M$ & IVA & خوش بينى \\
\hline$\cdot / \cdots 1$ & IVV & $r \varepsilon / T_{0}$ & $\varepsilon$ & $0 / 21 \pm \cdot / V V$ & IVA & سرمايه روانشناختى \\
\hline$\cdot / \cdot \cdot 1$ & IVV & $1 \mathrm{~V} / 01$ & $r$ & $r / 10 \pm \cdot / 70$ & IVA & ارزش ييشرفت \\
\hline$\cdot / \cdot \cdot 1$ & IVV &.$/ 1$ TO & r & $r / \cdot 1 \pm \cdot / 2 q$ & IVA & ارزش راحتى \\
\hline$\cdot / 20$ & IVV & $\cdot / \mathrm{V} 70$ & r & $r / \cdot \varepsilon \pm \cdot N r$ & IVA & ارزش پايخاه \\
\hline$\cdot 1 \cdot \cdot 1$ & IVV & $10 / 91$ & $r$ & $r / 7 V \pm \cdot / 07$ & IVA & ارزش دوستى \\
\hline$\cdot / \cdot 1$ & IVV & $1 / 79$ & r & $r / \Upsilon \Lambda \pm \cdot / \varepsilon \varepsilon$ & IVA & ايمنى \\
\hline$\cdot 1 \cdot \cdot 1$ & IVV & $r / \varepsilon \varepsilon$ & $r$ & $r / V \wedge \pm \cdot / \Lambda I$ & IVA & خودمختارى \\
\hline$\cdot / \mathrm{VV}$ & IVV & $\cdot / \mu$ & r & $r / 9 \Lambda \pm \cdot / 7 V$ & IVA & سبك ساز كارى \\
\hline.$\cdots 1$ & IVV & V/ro & $r$ & $r / r \mu \pm \cdot / \varepsilon r$ & IVA & ساز كارى شغلى \\
\hline
\end{tabular}

جدول شماره ب نشان داد بين همه مؤلفهاى سرمايه روان وجود دارد. بيشترين رابطه بين مؤلفه اميد و سازگارى

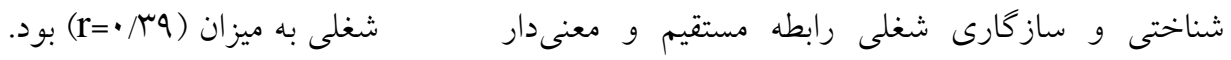

\begin{tabular}{|c|c|c|c|}
\hline $\mathbf{P}$ & $\mathbf{R}^{2}$ & $\mathbf{R}$ & متغير \\
\hline$\cdot / \cdot 1$ & .1 .97 & $\cdot \pi$ & خودكارآمدى و ساز كارى \\
\hline.$/ .1$ &.$/ 10$ & 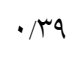 & اميد و سازگًارى \\
\hline.$/ .1$ & $\cdot / 1 \varepsilon$ & $\cdot \pi v$ & تاب آورى و ساز كارى \\
\hline$\cdot / . \cdot 1$ & $\cdot / 1 \varepsilon$ & $\cdot \mu v$ & خوش بينى و ساز كارى \\
\hline
\end{tabular}

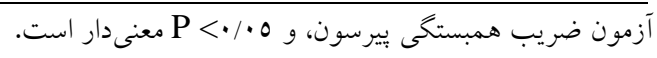

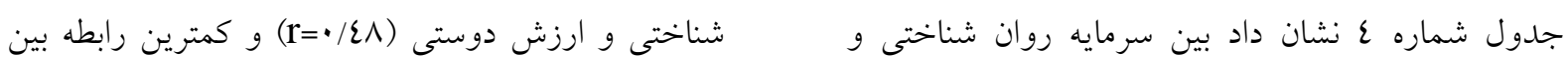

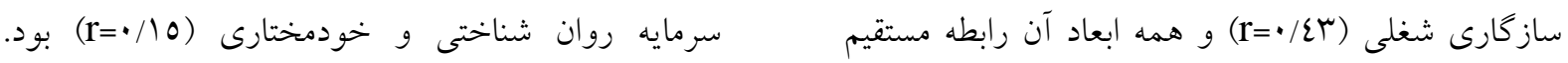
و معنى دار وجود دارد. بيشترين رابطه بين سرمايه روان

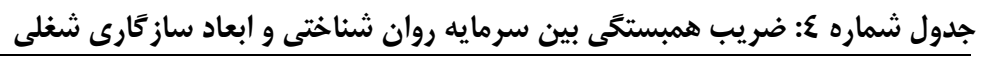

\begin{tabular}{|c|c|c|c|}
\hline 每 &.$/ \cdot$ ro & $\cdot / 17$ & سرمايه روان شناختى و ارزش بيشرفت \\
\hline$\cdot \cdots 1$ &.$/ 11$ & 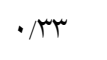 & سرمايه روان شناختى و ارزش راحتى \\
\hline$\cdot \cdots 1$ & $\cdot / r 1$ & $\cdot / 27$ & سرمايه روان شناختى و ارزش پايخاه \\
\hline$\%$ & $\cdot / \pi$ & $\cdot / \varepsilon \wedge$ & سرمايه روان شناختى و ارزش دوستى \\
\hline 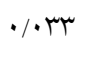 & $\%$ ro & $\cdot / 17$ & سرمايه روان شناختى و ايمنى \\
\hline$\cdot / \cdot \varepsilon \varepsilon$ & $\%$ ro & $\cdot 110$ & سرمايه روان شناختى و خودمختارى \\
\hline$\cdot \cdots 1$ & $\cdot / \varepsilon$ & $\cdot \mu \wedge$ & سرمايه روان شناختى و سبك ساز كارى \\
\hline$\cdot \cdots 1$ &.$/ 110$ & $\cdot / 2 r$ & سرمايه روان شناختى و ساز گارى \\
\hline
\end{tabular}


نريمانى سازكارى شغلى يرستاران زن شاغل در بيمارستان

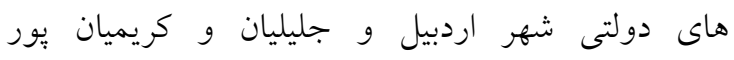

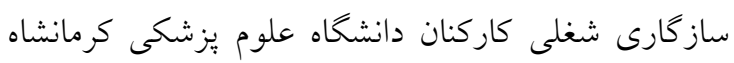

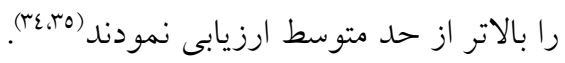

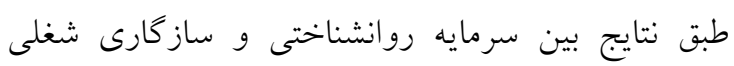

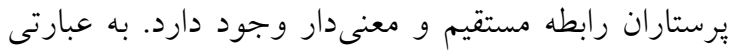
هر جهه وضعيت سرمايه روانشناختى در پرستاران بيشتر

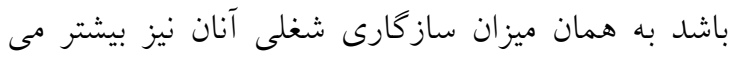
كردد. همجنين نظامى و گيوريان در بررسى تأثير سرمايه

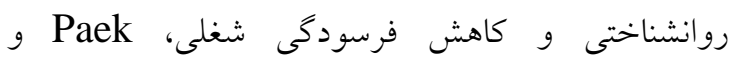
همكاران در بررسى تأثير سرمايه روان شناختى بر افزايش ورسئ

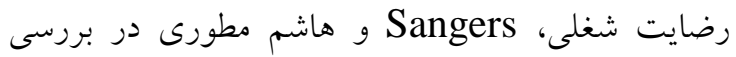

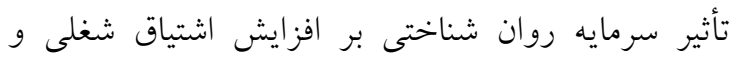

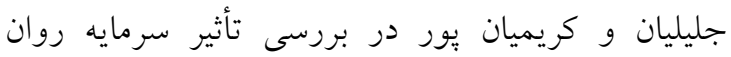

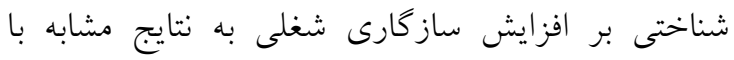

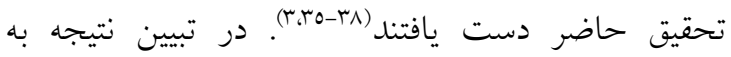
دست آمده، مىتوان كفت كه سازكارى شغلى شامل تطابق شخصيت فرد با عوامل محيطى كار است. نظريه

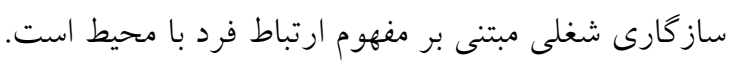

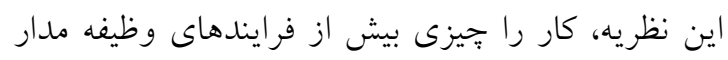

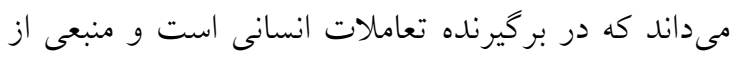
رضايت و ياداش را به وجود مى آورد. هر فردى انتظار دارد شغلش باعث خشنودى و سلامت و اعتبار وى رى

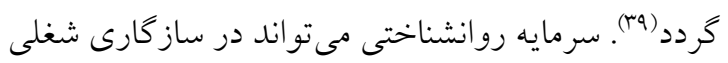
افراد مؤثر باشد. شايد بتوان بيان كرد كه سرمايه روان

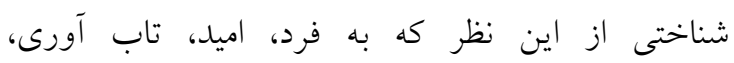
خودكارآمدى و خوش بينى مىدهد و ديدى كلى كلى در مورد

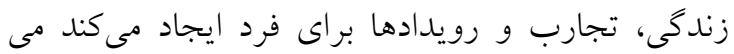
تواند باعث افزايش سازكارى شغلى شود. زيرا سرمايه

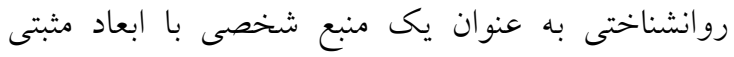

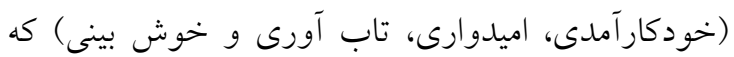
درون خود دارد به مقابله با يِيامدهاى منفى نظير استرس،

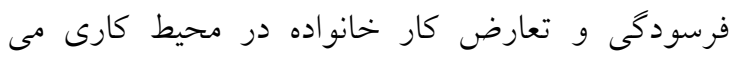

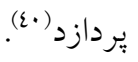

\section{بحث و نتيجه تيرى} يافتها نشان داد ميانخين سرمايه روان شيرى شناختى در دران

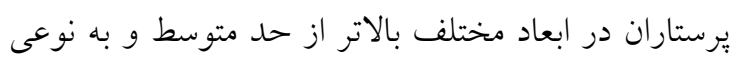

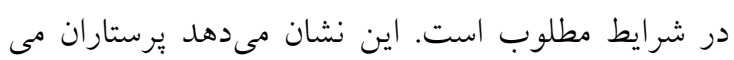

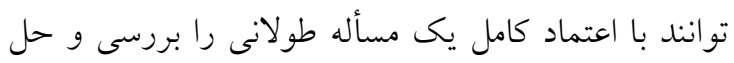

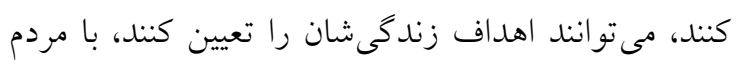

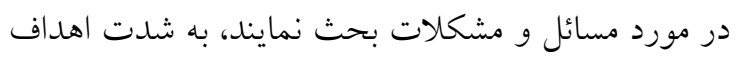

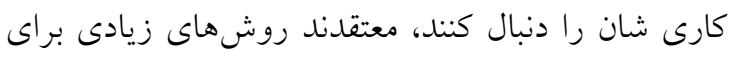

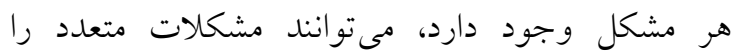

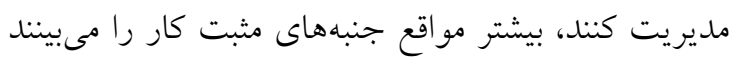

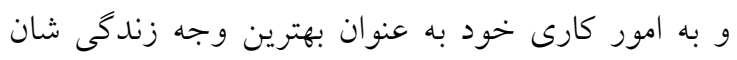

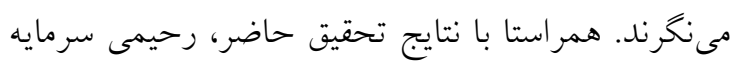

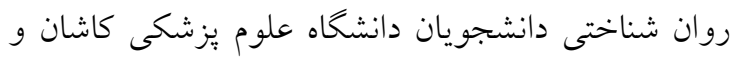

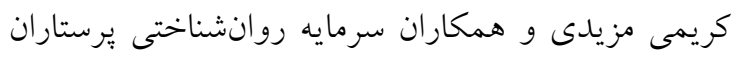

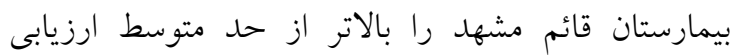

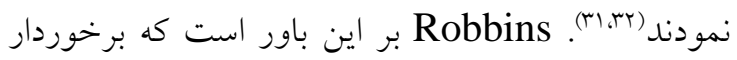

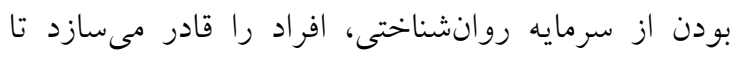

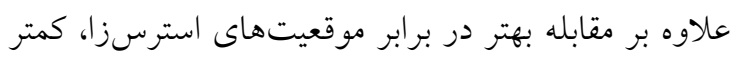

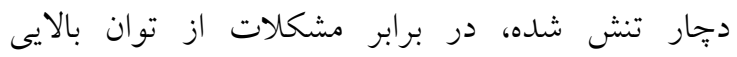

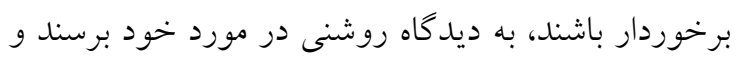

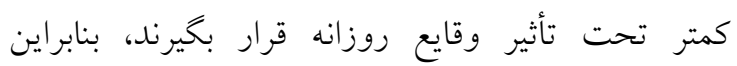
اين كونه افراد داراى سلامت روانشناختى بالاترى نيز

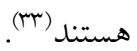
يافتهها نشان داد ميانخين سازكارى شغلى يرستاران در

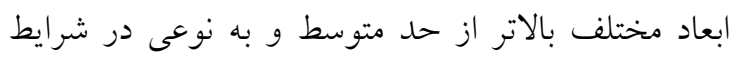
مطلوب است. اين نتايج گوياى اين است كه يرستاران دوست دارند هميشه به كارهاى مرتبط با شغلشان مشغول باشند، در شغلشان احساس بيشرفت كنند، از شرايط كارى شان رضايت نسبى دارند، معتقدند امكان ترقى و رفتن به مراحل بالاتر وجود دارد، با همكاران

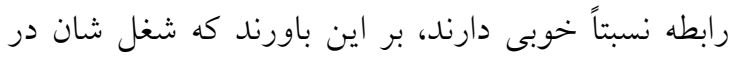
نظر مردم و جامعه، از جايعاه خوبى برخوردار است، از جالشهاى موجود در شغلشان لذت مىبرند و در شغل شان اقتدار نسبى و مناسبى دارند. همجنين صمدى فر و 


$$
\begin{aligned}
& \text { از روانشناسان و اساتيد مجرب در اين زمينه، دورههاى }
\end{aligned}
$$

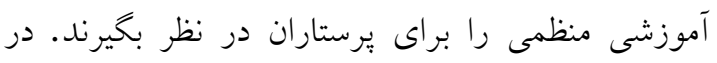

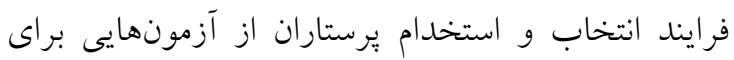

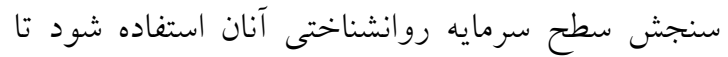

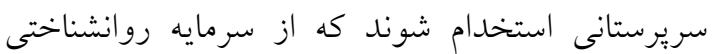

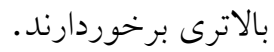$$
\text { بيان نشده است. منافع: هيج تعارض منافعى توسط نويسندكان }
$$

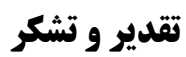

نويسندكان از تمام مسئولان و بِرستاران بيمارستانهاى

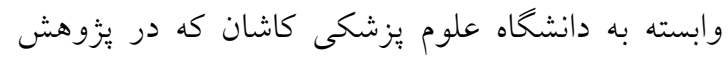

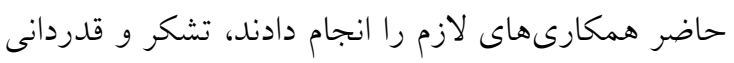

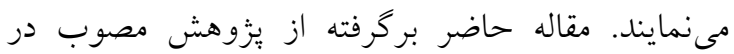

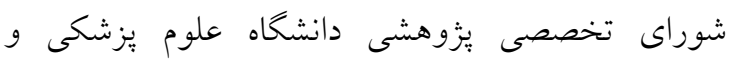

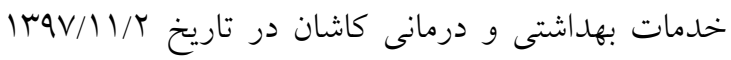
و با كد اخلاق

$$
\begin{aligned}
& \text { به طور كلى و بر اساس نتايج تحقيق مىتوان كفت كه }
\end{aligned}
$$

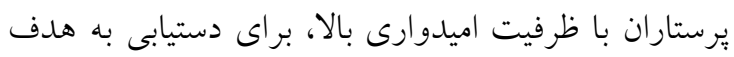

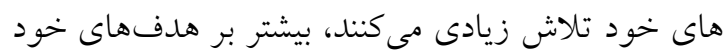

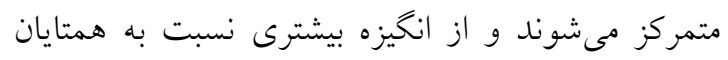

$$
\begin{aligned}
& \text { خود برخوردارند و خوشبينتر هستند. به علاوه، يرستاران }
\end{aligned}
$$

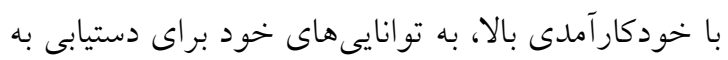

$$
\begin{aligned}
& \text { هدفهاى كارى و كسب تبحر و تسلط در زمينه كارى }
\end{aligned}
$$

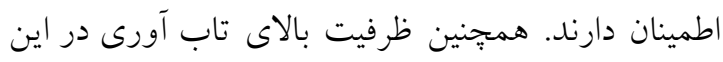

$$
\begin{aligned}
& \text { افراد باعث مىشود تا آنها نخرش متفاوتى در مواجهه با ديا } \\
& \text { موانع و جالشهاى كارى و ديخر موقعيتهاى زندكى اتخاذ } \\
& \text { كنند. نتايج اين بزوهش كوياى اين است كه در جامعائ } \\
& \text { يرستاران، به كارگيرى برنامههايى در جهت افزايش }
\end{aligned}
$$

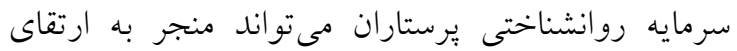

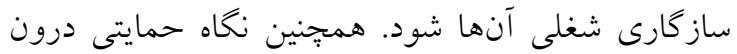

$$
\begin{aligned}
& \text { بيمارستانها و در نتيجه ادراى يرستاران از مورد حمايت }
\end{aligned}
$$

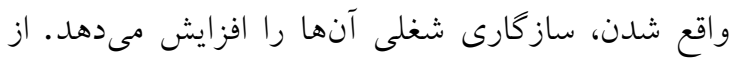

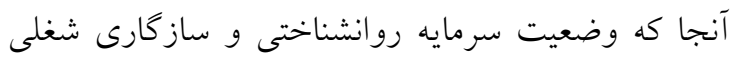

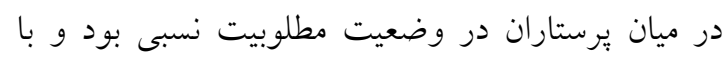

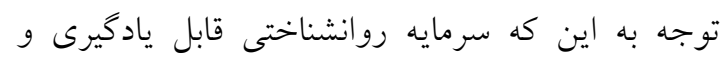

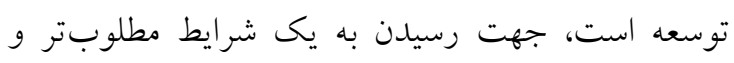

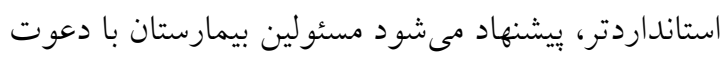

\section{References}

1. Tabataba'i-Nasab SM, Sabokro M, Fallahi MB. The effect of psychological capital on work engagement with mediating role of work-family conflict among nurses. Quarterly Journal of Nursing Management. 2017; 6(1):20-31. [Persian]

2. Laschinger HK. Job and career satisfaction and turnover intentions of newly graduated nurses. Journal of nursing management. 2012; 20(4):472-84.

3. Nezami A, Givarian H. An investigation of the effect of psychological capital on the burnout of nurses in a military hospital in Tehran. EBNESINA. 2016; 18(1):44-51. [Persian]

4. Strauser DR, Lustig DC. The moderating effect of sense of coherence on work adjustment. $J$ Employ Counse. 2003; 40(3):129-40.

5. Joolaee S, Jalili HR, Rafii F, Hajibabaee F, Haghani H. Relationship between moral distress and job satisfaction among nurses of Tehran University of Medical Sciences Hospitals. Journal of hayat. 2012;18(1):42-51. [Persian]

6. Kelbiso L, Belay A, Woldie M. Determinants of quality of work life among nurses working in Hawassa town public health facilities, South Ethiopia: A cross-sectional study. Nursing Research and Practice. 2017; 2017: 1-11.

7. Rahimi-Dadkan N, Nastiezaie N. Relationship among occupational adjustment, psychological empowerment and job burnout in faculty members. Research in Medical Education. 2017;8(4):19-28. [Persian] 
8. Bigharaz M, Bagheri G, Saberi A. The Status of Football Players'psychological Capital: The Role of Spiritual Leadership and Social Capital. Sport Psychological Studies, 2016;5(17):139-56. [Persian]

9. Luthans F, Vogelgesang GR, Lester PB. Developing the psychological capital of resiliency. Human Resource Development Review. 2006;5(1):25-44.

10. Dianat Nasab M, Javidi H, Baghooli $\mathrm{H}$. The role of mediating job stress in the relationship between psychological capital and job performance. Psychological Methods and Models. 2014;15(4):75-89. [Persian]

11. Luthans F, Avolio BJ, Avey JB, Norman SM. Positive psychological capital: Measurement and relationship with performance and satisfaction. Personnel psychology. 2007;60(3):541-72.

12. Avey JB, Luthans F, Jensen SM. Psychological capital: A positive resource for combating employee stress and turnover. Human resource management. 2009;48(5):677-93.

13. Avey JB, Luthans F, Smith RM, Palmer NF. Impact of positive psychological capital on employee well-being over time. J Occup Health Psychol. 2010;15(1):17-28.

14. Abolmaali Alhosseini K, Rostam Abadi F. Comparison of the Dimensions of the Psychological Capital of Athlete Women and non-Athlete. Health Research Journal. 2018;3(2):82-8. [Persian]

15. Sadoughi M, Mehrzad V, Mohammad Salehi Z. The relationship between psychological capital and quality of life among patients with breast cancer. Razi Journal of Medical Sciences. 2017;24(3):111-9. [Persian]

16. Soltani Z, Sadegh Mahboob S, Ghasemi Jobaneh R, Yoosefi N. Role of psychological capital in academic burnout of Students. Educ Strategy Med Sci. 2016;9(2):156-62. [Persian]

17. Ghane SA, Mirzazadeh Z, Azimzadeh S, Abdolmaleki H. The Role of Psychological Capital on Social Capital of Physical Education Students of Mashhad Universities. Applied Research of Sport Management. 2016;4(15):91-106. [Persian]

18. Salimi H, Azad-Marzabadi E, Abedi M. Determining the mental health condition and its correlation with job burnout and life satisfaction in a military university personnel. Ebnesina. 2010;13(3):10-7. [Persian]

19. Avey JB, Patera JL, West BJ. The implications of positive psychological capital on employee absenteeism. J Leadersh Organ Stud. 2006;13(2):42-60.

20. Neisi A, Arshadi N, Rahemi E. The Casual Relationship of Psychological Capital with Positive Emotions, Psychological Well-Being, Job Performance and Job Engagement. Journal of Psychological Achievements, 2011;4(1):19-46. [Persian]

21. Sun T, Zhao XW, Yang LB, Fan LH. The impact of psychological capital on job embeddedness and job performance among nurses: a structural equation approach. $J$ Adv Nurs. 2012; 68(1):6979.

22. Herbert M. An exploration of the relationships between psychological capital (hope, optimism, self-efficacy, resilience), occupational stress, burnout and employee engagement (Doctoral dissertation, Stellenbosch: Stellenbosch University). 2011.

23. Liu L, Chang Y, Fu J, Wang J, Wang L. The mediating role of psychological capital on the association between occupational stress and depressive symptoms among Chinese physicians: a cross-sectional study. BMC public health. 2012; 12(1):219-26.

24. Walumbwa FO, Luthans F, Avey JB, Oke A. Retracted: Authentically leading groups: The mediating role of collective psychological capital and trust. J organ behav. 2011 Jan; 32(1):4-24.

25. Silva D, Roche M. Contribution of psychological capital to entrepreneur's success during recessionary times. New perspectives in business research and education: New Zealand Applied Business Education Conference (NZABE); 27-28 September, Napier, New Zealand. 2010.

26. Hodges TD. An experimental study of the impact of psychological capital on performance, engagement, and the contagion effect. [PhD. of Thesis]. Lincoln, USA, University of Nebraska, 2010 .

27. Luthans F, Youssef CM, Avolio BJ. Psychological capital and beyond. Oxford University Press, USA; 2015.

28. Friend SB, Johnson JS, Luthans F, Sohi RS. Positive psychology in sales: Integrating psychological capital. Journal of Marketing Theory and Practice. 2016; 24(3):306-27. 
29. Ouweneel E, Le Blanc PM, Schaufeli WB. Do-it-yourself: An online positive psychology intervention to promote positive emotions, self-efficacy, and engagement at work. Career Development International. 2013; 18(2):173-95.

30. Dawis R. V., \& Lofquist L. H. A psychological theory of work adjustment. Minneapolis, MN: University of Minnesota Press. 1984.

31. Rahimi H. A Relationship between Spiritual Intelligence and Psychological Capital with Academic Performance among Students in Kashan University of Medical Sciences in 2016. Journal of Medical Education Development. 2017; 10(26):24-36. [Persian]

32. Karimi Mazidi A, Rezazadeh Barfouei H, Mortazavi S. The Effect of Employees' Psychological Capital on Their Emotional and Psychological Well-Being; Mediating Role of Positive Emotions, Stress, and Anxiety. Organizational Resources Management Research's. 2013; 3(3):90-110. [Persian]

33. Farhadi A, Saki K, Ghadampour E, Khalili GZ, Chehri P. Predictions Dimensions of Academic Engagement Based Capital Components Psychological. Educational Strategies. 2016;9(2):12733. [Persian]

34. Samadifard HR, Narimani M. The Relationship between Moral Identity, Spiritual Well-being and Religious Orientation with Job Adjustment among Nurses. Pajouhan Scientific Journal. 2018; 17(1):1-8. [Persian]

35. Jalilian S, Karimianpour G. The relationship between psychological capital and job adjustment of staffs in Kermanshah University of Medical Sciences (The study of mediator role of job selfefficacy). Pajouhan Scientific Journal. 2018; 16(3):39-47. [Persian]

36. Paek S, Schuckert M, Kim TT, Lee G. Why is hospitality employees' psychological capital important? The effects of psychological capital on work engagement and employee morale. Int $J$ Hosp Manag. 2015; 50:9-26.

37. Sengers N. The role of Psychological Capital in the Job Demands-Resources Model: Work Engagement and Turnover intention in an international contact centre environment (Master's thesis). Utrecht, Germany Utrecht University; 2013.

38. Matoori HH. Investigating the relationship between psychological capital and perceived organizational support with work engagement among nurses. Iran J Psychiatr Nurs. 2017; 5(2):45-51. [Persian]

39. Sohrabian A, Modaresi S, Yousefi F. The Relationship between Organizational Climate and Job Satisfaction among Occupied Nurses in Psychiatric Hospitals of Qods, Tohid and Besat. Shenakht Journal of Psychology and Psychiatry. 2018; 4(4): 34-43. [Persian]

40. Kan D, Yu X. Occupational stress, work-family conflict and depressive symptoms among Chinese bank employees: The role of psychological capital. Int J Environ Res Public Health. 2016; 13(1):134. 